\title{
Achievements and Implications of HIV Prevention Programme Among Out of School Youths: A Systematic Evaluation of HAF II Project in Bayelsa State, Nigeria
}

\author{
Ademola L. Adelekan ${ }^{1,8}$, Temple R. Iluma ${ }^{2}$, Nwodo P. Onyema ${ }^{3}$, Nnamani U. \\ Maranatha ${ }^{4}$, Prosper Okafor ${ }^{5}$, Kizito Andah ${ }^{6}$, Lawrence E. Clever ${ }^{7}$, Enuma \\ Charles $^{2}$, Adeyimika T. Desmennu ${ }^{8}$, Oladipupo Olaleye ${ }^{1,8}$, Diepreye Alagoa ${ }^{2}$, \\ Eunice Sammy-Boy ${ }^{2}$, Blessing Emmanuel ${ }^{2}$, Olusegun Adeoye ${ }^{9}$, Michael \\ Olugbile $^{9}$ \\ ${ }^{1}$ Blue Gate Public Health Promotion Initiative, Ibadan, Nigeria \\ ${ }^{2}$ Bayelsa State Agency for the Control of AIDS, Yenagoa, Nigeria \\ ${ }^{3}$ Chrismarax Health Care Initiative (CHCI), Yenagoa, Nigeria \\ ${ }^{4}$ Health Foundation International (HFI), Yenagoa, Nigeria \\ ${ }^{5}$ Centre for Development and Empowerment of Commercial Motorcyclists, Yenagoa, Nigeria \\ ${ }^{6}$ Kindling Hope Across Nations Initiatives, Yenagoa, Nigeria \\ ${ }^{7}$ Literacy Action Initiative, Yenagoa, Nigeria \\ ${ }^{8}$ Department of Health Promotion and Education, Faculty of Public Health, College of Medicine, University of \\ Ibadan, Ibadan, Nigeria \\ ${ }^{9}$ HIV Programme Development Project, World Bank, Abuja, Nigeria
}

\begin{abstract}
Background: Youths who do not attend school or who drop out are vulnerable to misinformation from unreliable sources or possibly never learn about the issues at all. In many communities, programs to reduce young people's risk of HIV infection and sexually transmitted diseases have been recommended. This paper presents achievements of HIV prevention programme among out of school youths (OSYs) in Bayelsa State, Nigeria.
\end{abstract}

Methods: This was an intervention project conducted among OSYs in Bayelsa State, Nigeria. Bayelsa State Agency for the Control of AIDS engaged five civil society organizations and funded under the HIV and AIDS fund (HAF) II project to provide HIV prevention among OSYs. The estimated total population was 62,300 OSYs and the program adopted the minimum prevention package intervention (MPPI) to implement project activities. Data collected were entered into the District Health Information Management System (DHIS2) platform and exported into Microsoft Excel for analysis using descriptive statistics.

Results: The total number of community dialogues held during this intervention was 81 and 1594 influencers participated. A total 28177 peers were registered and among these, 27805 were reached with HIV education. Overall, 174524 condoms were distributed and $68.5 \%$ of total male condoms and $74.8 \%$ female condoms were distributed in the second quarter. A total of 26005 (93.5\%) of the registered peers were reached with all the three stages of MPPI and $48774(78.3 \%)$ of the estimated sample size were reached with HCT. Among these, 223 $(0.5 \%)$ were tested positive to HIV

Conclusion: Implementation of the MPPI for HIV prevention showed significant improvement among out of school youths. However, there are still shortfalls in attainment of the expected results. It is therefore recommended that there should be increased integration of services and decentralization of minimum prevention package intervention activities to primary health care centers and rural communities while putting in place plans for sustainability and continuity of these programmes.

Key words: HAF II project, Minimum prevention package for intervention, Out of school youths, HIV/AIDS

I. INTRODUCTION 
Nigeria has the second largest HIV epidemic in the world [1]. Although HIV prevalence among adults is remarkably small (3.1\%) compared to other sub-Saharan African countries such as South Africa (19.2\%) and Zambia (12.9\%), the size of Nigeria's population means 3.5 million people were living with HIV in 2015 [2]. An estimated 60\% of new HIV infections in western and central Africa in 2015 occurred in Nigeria [2]. HIV prevalence is highest in Nigeria's southern states (known as the South-South Zone of which Bayelsa state is one), and stands at 5.5\% (NACA, 2015). In South/South zone, HIV prevalence is highest among age group 40 to $49(8.4 \%)$ followed by age groups 30 to $34(8.2 \%), 20$ to $24(8 \%), 25$ to $29(7 \%), 15$ to $19(5.3 \%)$ and 35 to 39 (5.2\%) [2]. The HIV prevalence of Bayelsa State in 2005 was 3.8\% and presently it has increased to about 7.2\% [3]. Many factors are responsible for an increase in HIV prevalence in Bayelsa State which includes poverty, lack of economic and financial empowerment of women, socio-cultural practices such as wife inheritance, polygamy, female genital mutilation, unprotected sex, partner sharing in some communities and largely of behavioral change in spite of knowledge and awareness [4]. Another factor contributing to the spread of HIV and AIDS in Bayelsa State is the difficult terrain. Lots of rural communities are not accessible by road but by boat due to the riverine nature and boat transportation is usually very expensive. This has made access to comprehensive HIV and AIDS prevention, treatment and care and support services in the State very difficult for those living in these rural areas [4].

HIV prevalence by age sentinel survey 2008 revealed that young people aged 25-29 years have prevalence of $5.6 \%$, followed by middle aged adults between the ages 30-34 years which have a prevalence of $4.9 \%$ [4]. Recent national data suggests that $4.2 \%$ of young people (ages 15-24) are living with HIV [4]. There is generally a poor health seeking behavior for STIs among populations including vulnerable populations encompassing the out-of-school populations in the State. Despite the high level of sensitization on HIV and AIDS in the State only $22.8 \%$ of the population have knowledge of HIV/AIDS [5]. Generally, stigma and discrimination, myths and misconceptions about HIV/AIDS are still widespread. Only $49.1 \%$ of population are willing to share meals with HIV infected persons, $46.2 \%$ of respondents in the States are willing to buy food from HIV infected persons [5]. Therefore, there is need to shift focus from basic awareness raising strategies to strategies that will translate to improved and comprehensive knowledge about HIV/AIDS. The rapid community assessment of HIV/AIDS situation conducted in Bayelsa State revealed the indices of high risk-taking behaviours such as traditional practices/customs/beliefs; unprotected sex and multiple sexual partners, with high incidence and related complications such as STIs and HIV/AIDS infections increased the incidence in the State [6]. There is a need therefore to increase access to condoms and promote its correct and consistent use for the prevention of new infections especially among the youths in the State. Considering the aforementioned, it is thus necessary to put in place interventions, strategies and methods towards successful implementation of HIV prevention activities. The goal of this project was therefore to reduce the risk of HIV infections by scaling up prevention interventions and increase access to and utilization of HIV testing, counseling, care and support services. This paper presents achievements of HIV prevention programme among OSYs in Bayelsa State, Nigeria.

\section{METHODOLOGY}

\section{Study Design}

This was an intervention project conducted among OSYs in Bayelsa State, Nigeria. It used descriptive cross-sectional design for its preliminary data collection for the needs assessment before the implementation of this intervention. Bayelsa State Agency for the Control of AIDS (BYSACA) engaged five Civil Society Organizations (CSOs) namely Centre for Development and Empowerment of Commercial Motorcyclists (CEDECOM), Chrismarax Health Care Initiative (CHCI), Literacy Action Initiative (LAI), Health Foundation International (HFI) and Kindling Hope Across Nations Initiatives (KHAN). The CSOs were funded under the HIV and AIDS fund (HAF) II project to deliver evidence-informed HIV intervention packages in line with international standards and best practices. Furthermore, the CSOs were expected to create demand for the available services and initiate a means by which the communities can own and sustain the projects.

\section{Study Area}

Bayelsa was carved out of Rivers State in 1996 and is situated in Niger Delta of the South-South geographical zone of Nigeria. It shares boundaries with Delta State on the North, Rivers State on the East and the Atlantic Ocean on the West and South. It is a picture square tropical rain forest, with a total land area of 9,656 square kilometers. More than three quarters of this (8453 square kilometers) area is occupied by waters and is predominately riverine, full of lakes, creeks, swamps and marshy land, with moderately low land stretching from Ekeremor to Brass Local Government Areas. Bayelsa State is a major oil and gas producing area and contributes to over $30 \%$ of Nigeria's oil production. The state has 8 Local Government Areas including Yenagoa, Brass, Nembe, Ogbia, Sagbama, Kolokuma/Opokuma, Ekeremor and Southern Ijaw. Bayelsa State covers an area of 9,415.8 square kilometers. It lies at latitude $4^{\circ} 45^{\prime}$ north and longitude $6^{\circ} 05^{\prime}$ east. It has a 
population of 1,704,515 (2006 census figures) with a population density of 158 people per square kilometer; it accounts for $1.2 \%$ of Nigeria's total population [7].

\section{Study population}

The target population for this intervention consisted of OSYs in all the eight LGAs in Bayelsa state who had never attended school or were not enrolled in any school as at the time of this project. Some of these have at one time or the other acquired some forms of education but dropped out of school due to various reasons, they were either learning a trade or were apprentice artisans. Others were Okada (motorcycle) or Keke (tricycle) riders.

\section{Sample size}

The estimated total population of this target group was 62,300 OSYs

\section{Sampling Techniques}

The project adopted a purposive sampling technique; youth groups in each of the selected LGAs were identified using a community participatory approach, peer educators were selected by nomination of qualified persons who were acceptable by the youth community.

\section{Intervention}

The programme adopted the use of minimum prevention package intervention (MPPI) and activities were classified under structural, behavioural, biomedical interventions. The project composition package for this intervention included IEC materials for HIV risk reduction, HIV counseling and testing (HCT), STI's referral and treatment, referral for HIV treatment and condom promotion. Activities conducted under each of the three levels of MPPI were as follows:

\section{Structural Intervention}

Structural interventions carried out include: advocacy, community mobilisation and coordination Meeting. Advocacy visits were made to health facilities and community stakeholders to strengthen their ties and ease referrals within the state. In strengthening and supporting institutions to strategically linking HIV prevention intervention through the project, series of meetings were held and linkages were promoted through meetings between staffs of the medical centre and the project team that enhanced collaboration and experience sharing. Community dialogue meetings were also held to keep the groups abreast with care and support; effective networking and leveraging of ideas and support were encouraged.

\section{Behavioural Intervention}

These involved out of school sensitization activities, peer educators' recruitment, training and condom distribution. It focused mainly on the recruitment of peer educators through a snow balling of peers in artisan and apprenticeship settings. Some of these were also recruited from youth development organisations within the selected communities. Peer educators were trained on HIV prevention modules suitably communicated by professionals in the field of public health. Peers were also intimated on the requirement and importance of cohort sessions in which each peer educator was expected to reach at least 10 peers. Each of the peer educators was expected to have six to nine contact periods with his/her peers to meet up with MPPI. Data were documented by the peer educator using various data collection and reporting tools.

\section{Biomedical Intervention}

HIV counselling and testing (HCT) was carried out by trained HIV counsellor testers. During the testing, counselling services were provided to clients and basic information on HIV and AIDS were also provided to the clients. Condoms were distributed to clients who required it and those who tested positive for HIV were referred for further services while those with high risky sexual behaviour were referred for STIs services which include sexuality education and counselling. Data were documented using client intake forms, referral forms and register.

\section{Monthly Monitoring and Evaluation visit to project sites}

Monitoring and information system were put in place through tracking forms supplied by the National Agency for Control of AIDS (NACA). Desk review of the collated data from the trained peer educators was conducted to ensure data quality for effective compliance to project goals and objectives. 


\section{Data Analysis}

Data collected using other Monitoring and Evaluation tools were collated and summarised with the aid of National Monthly Prevention Summary form. It was later entered into the District Health Information Management System (DHIS2) platform and exported into Microsoft Excel and analysed using same. Data were analysed using descriptive statistics and presented in tables and charts.

\section{Ethical Consideration}

Prior to the commencement of the research, the proposal was subjected to a two-stage review and ethical approval to conduct the research was obtained from the National and the State Ethical Review Committee, Federal Ministry of Health, Nigeria after an in-depth review of the proposal for compliance with ethical guidelines. Also, permission was obtained from the leaders of the identified groups where necessary. The criteria for selection of samples included voluntary declaration of participation in the study and the ability for transmission of information. Informed consent was obtained from all participants in the study; this included statements of assurance of confidentiality of the all information collected from the participants. Verbal informed consent was obtained from everyone who was mobilised for HCT. It was also emphasized that HIV testing was voluntary; confidentiality and anonymity rules were complied with.

\section{Structural Intervention}

\section{RESULTS}

Table 1, shows the summary of activities carried out during the project which could be categorised as structural indicators. The total number of community dialogues held during this intervention was 81 ; many of these $(77.8 \%)$ were held during the first quarter of the project. With regards to community influencers who participated in the community dialogues, 1594 participated; out of this $59.0 \%$ were recorded in the first quarter of the project.

Table 1: Structural Intervention indicators

\begin{tabular}{|c|c|c|}
\hline \multirow{2}{*}{$\begin{array}{c}\text { Period of } \\
\text { Assessment }\end{array}$} & $\begin{array}{c}|c| \\
\text { Numbers of community } \\
\text { dialogues held n (\%) }\end{array}$ & $\begin{array}{c}\text { Number of influencers who } \\
\text { participated in community } \\
\text { dialogue } \mathbf{n}(\%)\end{array}$ \\
\cline { 2 - 3 } & $63(77.8)$ & $940(59.0)$ \\
\hline $1^{\text {st }}$ quarter & $18(22.2)$ & $654(41.0)$ \\
\hline $2^{\text {nd }}$ quarter & $\mathbf{8 1}$ & $\mathbf{1 5 9 4}$ \\
\hline Total & & \\
\hline
\end{tabular}

\section{Behavioural Intervention}

The main behavioural indicator for the project with information targeted at behavioural changes among the out-of-school youths are shown in table 2. With regards to total number of peers registered, 28177 peers were registered and most (65.6\%) were reached during the second quarter of the project. About $12386(64.6 \%)$ of the total male and $6110(67.8 \%)$ of the total female peers were registered during the second quarter of the project. Among the registered peers, a total of 27805 were reached with HIV education (Table 2).

Table 2: Behavioural Intervention indicators

\begin{tabular}{|l|c|c|c|c|c|c|}
\hline \multirow{2}{*}{$\begin{array}{l}\text { Period of } \\
\text { Assessment }\end{array}$} & \multicolumn{3}{|c|}{$\begin{array}{c}\text { Number of peers registered } \\
\text { n (\%) }\end{array}$} & \multicolumn{2}{c|}{$\begin{array}{c}\text { Number of persons reached with } \\
\text { HIV education n (\%) }\end{array}$} \\
\cline { 2 - 7 } & Male & Female & Total & Male & Female & Total \\
\hline $\mathbf{1}^{\text {st }}$ quarter & $\begin{array}{c}6782 \\
(35.4)\end{array}$ & $\begin{array}{c}2899 \\
(32.2)\end{array}$ & $\begin{array}{c}9681 \\
(34.4)\end{array}$ & $\begin{array}{c}9592 \\
(51.8)\end{array}$ & $\begin{array}{c}4231 \\
(45.5)\end{array}$ & $13823(49.7)$ \\
& 12386 & $\begin{array}{c}6110 \\
(67.8)\end{array}$ & $\begin{array}{c}18496 \\
(65.6)\end{array}$ & $\begin{array}{c}8922 \\
(48.2)\end{array}$ & $\begin{array}{c}5060 \\
(54.5)\end{array}$ & $13982(50.3)$ \\
\hline $2^{\text {nd }}$ quarter & $(64.6)$ & $\mathbf{9 0 0 9}$ & $\mathbf{2 8 1 7 7}$ & $\mathbf{1 8 5 1 4}$ & $\mathbf{9 2 9 1}$ & $\mathbf{2 7 8 0 5}$ \\
\hline Total & $\mathbf{1 9 1 6 8}$ & $\mathbf{9 0 0 9}$ & & & & \\
\hline
\end{tabular}

\section{Biomedical Intervention}

A major aspect of this project was the biomedical intervention which quantifies the uptake of other components of the intervention in the quantity of male and female condoms distributed, number of individuals counseled tested and received results for HIV, number of individuals referred for ART and STI treatment. Table 
3 which showed a comparative analysis of these activities. For most of the indicators measured, better results were obtained during the second quarter compared to the first. Overall, $68.5 \%$ of total male condoms and $74.8 \%$ female condoms were distributed in the second quarter. In comparison with the total condom required, $82.5 \%$ were met in the first quarter while barely half $(53.9 \%)$ of condom requirement were met during the second quarter. Ninety-nine percent of OSYs who were receiving STI services was during the first quarter. However, with regards to persons who were counseled, tested and received results for HIV and those receiving STI services, more (99.0) were attended to during the first quarter than the second quarter (1.0\%).

Table 3: Biomedical Intervention indicators

\begin{tabular}{|c|c|c|c|c|c|c|c|c|c|}
\hline \multirow[b]{2}{*}{ 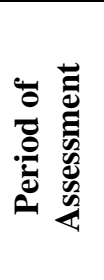 } & \multicolumn{9}{|c|}{ Indicators } \\
\hline & 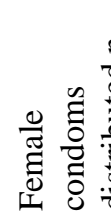 & 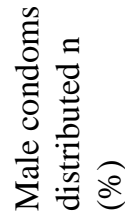 & 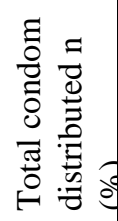 & 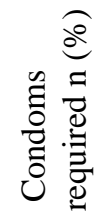 & 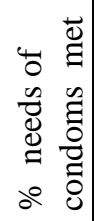 & 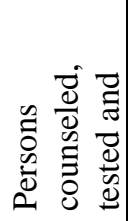 & 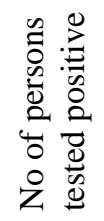 & 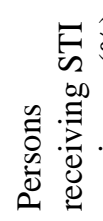 & 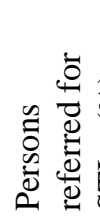 \\
\hline & & & & & 82.5 & 1.6) & $\begin{array}{c}108 \\
(48.4 \\
)\end{array}$ & $\begin{array}{c}301 \\
(99.0 \\
)\end{array}$ & $\begin{array}{c}0 \\
(0.0)\end{array}$ \\
\hline $\begin{array}{l}\mathbf{2}^{\text {nd }} \\
\text { quarte }\end{array}$ & 2522 & $\begin{array}{c}10812 \\
3 \\
(68.5)\end{array}$ & $\begin{array}{c}12064 \\
5 \\
(69.1)\end{array}$ & $\begin{array}{c}22390 \\
0 \\
(77.4)\end{array}$ & 53.9 & & $\begin{array}{c}115 \\
(51.6 \\
)\end{array}$ & $\begin{array}{c}3 \\
(1.0)\end{array}$ & $\begin{array}{c}414 \\
(100 . \\
0)\end{array}$ \\
\hline Total & 5746 & $\begin{array}{c}15777 \\
8\end{array}$ & $\begin{array}{c}17452 \\
4\end{array}$ & $\begin{array}{c}28923 \\
0\end{array}$ & 60.3 & 48774 & 223 & 304 & 414 \\
\hline
\end{tabular}

\section{Coverage of MPPI, HCT and Prevalence of HIV}

A total of $26005(93.5 \%)$ of the registered peers were reached with all the three stages of MPPI and 48774 $(78.3 \%)$ of the estimated sample size were reached with HCT. Among these, $223(0.5 \%)$ were tested positive to HIV (Fig. 1).

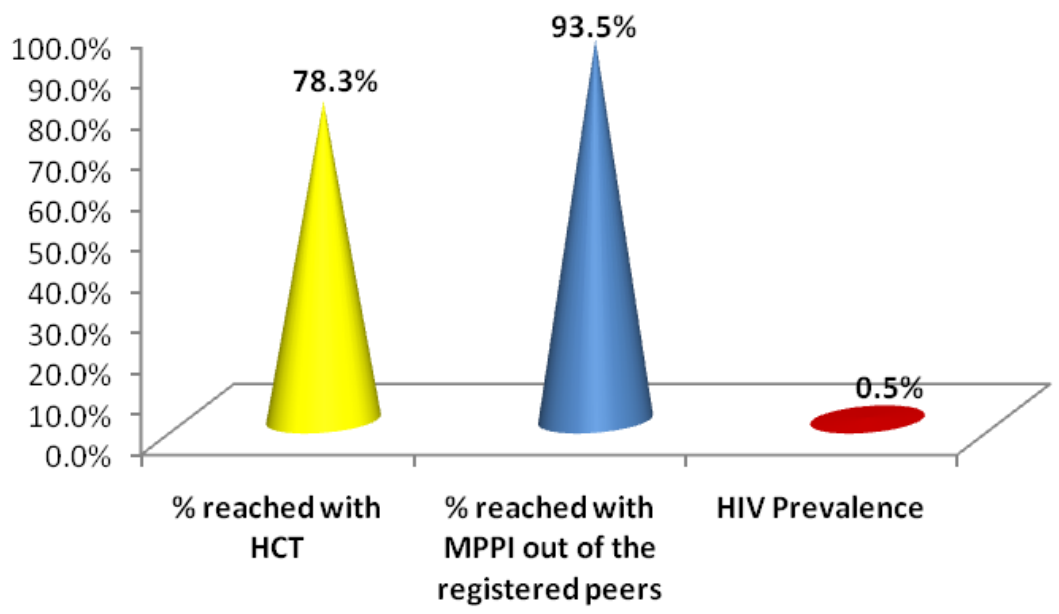

Figure 1: Coverage of MPPI, HCT and Prevalence of HIV

\section{DISCUSSION}

In conformity with the recommendation of the UNICEF [8], the minimum package prevention intervention for HIV with its main components of intervention was adopted and implemented for HIV prevention programming in Bayelsa State, Nigeria. This strategy which proved to be a successful strategy among the most at risk populations (MARPs) as reported in a study carried out among Injection Drug Users (IDUs) in Burma [9] and female sex workers (FSWs) in Benue state Nigeria [10] was carried out in the state in the year 2016 on a quarterly basis. In accordance with the recommendation of UNICEF [8], community mobilisation, outreaches, advocacy and partnership for monitoring are very important for a successful HIV prevention programme especially among OSYs who are mobile and vulnerable to infection. The multi-pronged approach of this study confirms that the best prevention strategy is an expanded response which simultaneously 
reduces vulnerability, risk behaviour and the impact of the infection [8]. A comprehensive community mobilization and advocacy laid a very good foundation for the proper implementation of the work-plan of the project. This was vivid in the number of community dialogues, advocacy and mobilisations held with a corresponding high number of community influencers reached for the project. As the project advances, this number tends to reduce thereby signifying a very comprehensive and successful community entry process. This is confirmed in the report of an HIV prevention programme in Zimbabwe [11] which showed a gentle decline in recruitments made for outreaches by implementers as the year turned over.Behavioural data from this evaluation revealed a general increase in the number of peers reached in second quarter compared to those reached in first quarter. This has only revealed an improved programme output. In comparison with the size estimation of the target population, about $45.2 \%$ of the peers were registered which was far below the estimated target population. This is a major indicator for a scale-up in registration and recruitment of peers for an improved and impactful behavioural intervention component of the MPPI. Also, regarding distribution of both male and female condoms, although there appears to be distribution of high number of both the female and the male condoms mostly during the second quarter, a comparison with number of condoms required still showed a shortfall of almost half. This has presented a great challenge for condom programme for the behavioural component of the MPPI strategy for HIV prevention. As reported in the Nigeria Demographic and Health Survey [12], condom use is one of the most effective strategies for combating the spread of HIV and other sexually transmitted infections [12]. The number of peers reached with HCT is far above the number of peer registered. This is an indication that many of the peers only utilized HCT service without benefitting from HIV education of the behavioural component. It should however be noted that the overall MPPI programme evaluation could be said to have achieved below expectation; this results has revealed a significant gap in the programme implementation and a need for a more holistic and comprehensive HIV prevention programming.

\section{Implications for Programming}

An overview of the evaluation of the HIV prevention programme in Bayelsa state has revealed some gaps in the programming and implementation process. Some challenges associated to successful implementation of the MPPI in the state included lack of income generation activities (IGAs) conducted for the OSY. Income generating activities are tested medium through which OSYs could be empowered and thereby enabling them to take proper decisions for health. Therefore, it would be suggested that the Bayelsa state government should consider the introduction of IGAs to these youths since this will make them to be self-reliant thus having positive influence on the society. Also, it could be observed that there was increased demand for condom especially the female condoms. These should be made readily available to these youths at reduced priced. This would enable them diverse options for safer sex for both the males and females and also to increase the ability of the females for condom negotiation. Although the project tried to cover all the LGAs in Bayelsa state, it is very important that government should sustain this project and plan for a scaling up to reach the unreached in the current programme. It is also very important that the communities have a buy-in on the programme in order to ensure continuity and sustainability of HIV prevention by community members such that by the time funding ceases, programme would still continue to progress. The State Government should also take ownership of the programme by providing ARV drugs, male and female condoms, requisite infrastructure, adequate staffing and the capacity building of health care providers at the primary health care level.

\section{CONCLUSION}

Effective implementation of the HIV and AIDS Minimum Prevention Package Intervention (MPPI) in Bayelsa state that focuses on individuals and community behaviour showed significant improvement during the second quarter of the project when the indicators for the three levels of prevention were compared. However, relating these achievements to the total estimated population of the target group still revealed shortfalls in the attainment of the expected results. This is largely due to programmatic bottlenecks, which when given the necessary attention could be easily overcome. It is therefore recommended that there is increased integration of services and decentralization of MPPI activities to primary health care centers and rural communities, stepwise supervision and monitoring of HIV prevention activities should be strengthened and engagement of all tiers of governance to engender political commitment and ownership of the HIV response (including State and Local Government Area (LGA levels) with a view to ensure the sustainability of these programmes.

\section{ACKNOWLEDGEMENT}

The evaluation team wishes to acknowledge the World Bank and the National Agency for the Control of AIDS (NACA) for making available the funding for the evaluation and dissemination of this project intervention. Special appreciation goes Alex Ogreagade, Claude Ujile and Weniebi Zibiya for their support during this project implementation. 


\section{REFERENCES}

[1] National Agency for the Control of AIDS (NACA ) (2015) 'Nigeria GARPR 2015' GLOBAL AIDS RESPONSE Country Progress Report Nigeria GARPR 2015

[2] UNAIDS (2016) 'Prevention Gap Report'

[3] Bayelsa State Agency for control of AIDS (BSSACA), Preliminary survey 2012

[4] National Agency for the Control of AIDS (NACA). 2015. Federal Republic of Nigeria, Global AIDS Response - Country Progress Report.

[5] Federal Ministry of Health. National Reproductive and Health Survey Plus (NARHS PLUS), 2012. 8 11

[6] Bayelsa State Ministry of Health and FHI 360. 2013. Bayelsa State-wide Rapid Health Facility Assessment, Nigeria: Bayelsa State Ministry of Health and FHI 360.

[7] Bayelsa State Portal, 2016) Facts about Bayelsa

[8] UNICEF (2004). What works for children in South Asia, HIV prevention among young people. Pgs 1 27

[9] USAID (2007). Evidence for a successful implementation of the minimum package of HIV preventions interventions in Burma. A report prepared by Bessinger R, Chan MMN, Longfield K, Aung T and Rahman H. USAID

[10] Songu, G. S (2013). Minimum prevention package intervention; A workable strategy for achieving behaviour change amongst vulnerable population and most at risk population (MARPS) in Benue State. J. AIDS. Clin. Res; 4:9

[11] Restless Development (2014). Scaling up SRH and HIV/AIDS prevention programmes among the young people in selected riral communities of Zimbabwe. End of project Evaluation report. Pg 1-46

[12] National Population Commission Nigeria (2009). Nigeria Demographic and Health Survey 2008. Calverton, Maryland: National Population Commission and ORC/Macro. 